\title{
Nanoparticle formation by ozonolysis of inducible plant volatiles
}

\author{
J. Joutsensaari ${ }^{1}$, M. Loivamäki ${ }^{2,3}$, T. Vuorinen ${ }^{2}$, P. Miettinen ${ }^{4}$, A.-M. Nerg ${ }^{2}$, J.K. Holopainen ${ }^{2}$, and A. Laaksonen ${ }^{4}$ \\ ${ }^{1}$ Department of Environmental Sciences, University of Kuopio, P.O. Box 1627, FIN-70211 Kuopio, Finland \\ ${ }^{2}$ Department of Ecology and Environmental Science, University of Kuopio, P.O. Box 1627, Kuopio FIN-70211, Finland \\ ${ }^{3}$ Institute for Meteorology and Climate Research - Atmospheric Environmental Research (IMK-IFU), Kreuzeckbahnstrasse \\ 19, 82467 Garmisch-Partenkirchen, Germany \\ ${ }^{4}$ Department of Applied Physics, University of Kuopio, P.O. Box 1627, FIN-70211 Kuopio, Finland
}

Received: 25 November 2004 - Published in Atmos. Chem. Phys. Discuss.: 10 January 2005

Revised: 2 May 2005 - Accepted: 16 May 2005 - Published: 16 June 2005

\begin{abstract}
We present the first laboratory experiments of aerosol formation from oxidation of volatile organic species emitted by living plants, a process which for half a century has been known to take place in the atmosphere. We have treated white cabbage plants with methyl jasmonate in order to induce the production of monoterpenes and certain less-volatile sesqui- and homoterpenes. Ozone was introduced into the growth chamber in which the plants were placed, and the subsequent aerosol formation and growth of aerosols were monitored by measuring the particle size distributions continuously during the experiments. Our observations show similar particle formation rates as in the atmosphere but much higher growth rates. The results indicate that the concentrations of nonvolatile oxidation products of plant released precursors needed to induce the nucleation are roughly an order-of-magnitude higher than their concentrations during atmospheric nucleation events. Our results therefore suggest that if oxidized organics are involved in atmospheric nucleation events, their role is to participate in the growth of pre-existing molecular clusters rather than to form such clusters through homogeneous or ion-induced nucleation.
\end{abstract}

\section{Introduction}

The largest uncertainties in forward calculations of warming of the atmosphere due to greenhouse gases are related to our limited knowledge of negative solar radiative forcing associated with aerosols (Anderson et al., 2003). Formation of secondary organic aerosols (SOA), i.e., particle production from volatile organic compounds (VOCs) by chemical reactions, is one of the main processes that affect the composition and properties of atmospheric particles. Recent esti-

Correspondence to: J. Joutsensaari

(jorma.joutsensaari@uku.fi) mates on the importance of SOA formation show that it may be significant when compared to the primary organic aerosol emissions: about $60 \%$ of the organic aerosol mass is SOA on the global scale and regionally even more (Kanakidou et al., 2004).

Volatile monoterpenes and isoprene, which are the main biogenic VOCs in the atmosphere, are known to contribute to SOA formation (Claeys et al., 2004; Kanakidou et al., 2004; Kavouras et al., 1998). The current evidence from reaction chamber studies (Bonn and Moortgat, 2003) suggests that inducible VOCs with low volatility such as sesquiand homoterpenes might be even more effective in reactions with $\mathrm{O}_{3}$ and subsequent formation of aerosol particles. Substantial increases in total terpene emissions from plants have been detected after herbivore-feeding damage (Vuorinen et al., 2004b). Furthermore, plants damaged by insects (Vuorinen et al., 2004b) or ozone (Vuorinen et al., 2004a) start to emit certain less-volatile sesqui- and homoterpenes which are not emitted in substantial amounts from intact plants. An increase in the amount of biogenic VOCs can significantly affect SOA formation locally, e.g., during air pollution episodes. Furthermore, these inducible VOCs act as an indirect plant defense by attracting the natural enemies of herbivores (Dicke and van Loon, 2000; Holopainen, 2004).

It has recently become apparent that nucleation events forming new aerosol particles occur in a wide variety of boundary layer environments around the world (Kulmala et al., 2004). The observed nucleation and growth rates of the freshly formed particles appear to be surprisingly similar everywhere. If oxidized organics formed from plant released precursors are involved in the particle growth (as is commonly believed), this indicates that the physicochemical properties (especially vapor pressures) of the participating species are quite similar, even if the species are not always the same. It could therefore be argued that features of nucleation and growth observed after oxidation of VOCs emitted by one plant species can be used to draw conclusions

(C) 2005 Author(s). This work is licensed under a Creative Commons License. 
on similar nucleation from the emissions of other plants.

Here, we present the first laboratory demonstration of aerosol nucleation from oxidation of volatile organic species emitted by living plants. We have measured particle formation over chemically treated cabbage plants during ozone pulses. The plants were treated with methyl jasmonate elicitor to increase and induce emissions of different terpenes. We show that a more likely role for oxidized organics than their homogeneous or ion induced nucleation is their participation in the growth processes of freshly formed atmospheric particles.

\section{Experimental}

White cabbage (Brassica olearacea subspecies capitata, cultivars Lennox and Rinda) plants were used as a source of biogenic VOCs in our experiments. Cabbages are important crop plants cultivated in both hemispheres, and as constitutive monoterpene emitters with inducible sesqui- and homoterpene emissions (Mattiacci et al., 1995; Vuorinen et al., 2004b) suitable test plants for VOC experiments. Cabbage plants were used in two different experiments: i) aerosol formation experiments to determine new particle formation during ozone pulses over chemically treated plants, and ii) VOC emission analyses to determine VOC emissions from individual intact (control) and treated plants (induced emission). We used methyl jasmonate (MeJA) treatment (Loivamäki et al., 2004) to initiate an emission spectrum of terpenes that is typical to herbivore-damaged plants (Vuorinen et al., 2004b).

\subsection{Plant material and treatments}

Seedlings of white cabbage (cultivars Lennox and Rinda) were individually sown in 1-1 plastic pots filled with Sphagnum peat and sand $(3: 1 \mathrm{v} / \mathrm{v})$ and pre-grown in a greenhouse for 28 days. The plants were then transferred into computer controlled growth chambers (Bioklim 2600T, Kryo-Service Oy, Helsinki, Finland) (Holopainen and Kärenlampi, 1984) and maintained at $23: 18^{\circ} \mathrm{C}, 70: 80 \%$ relative humidity and $22 \mathrm{~h}$ light: $2 \mathrm{~h}$ dark photoperiod $\left(250 \mu \mathrm{mol} \mathrm{m}^{-2} \mathrm{~s}^{-1}\right.$ PAR during light period). Separate plants were used for VOC analyses and aerosol formation experiments with $\mathrm{O}_{3}$ pulses.

To enhance emissions of monoterpenes ( $\mathrm{C} 10$ terpenes) and to induce emissions of homoterpenes (acyclic terpenes derived from sesqui- or diterpenes) and sesquiterpenes (C15 terpenes), the cabbage plants were sprayed with an aqueous MeJA solution ( $10 \mathrm{mmol}$ water solution, approx. $7 \mathrm{ml}$ per plant) about 2-4 days before the experiments. VOCs were analyzed individually from intact (control plants) and MeJAtreated cabbages.

\subsection{VOC analyses of individual plants}

VOC emissions of the control and MeJA-treated cabbages were measured from five plants for both cultivars (Lennox and Rinda). Before sampling the root system of the plant was rinsed and slightly pruned and placed in a $15 \mathrm{ml}$ vial filled with tap water. The plants were individually enclosed inside 1-1 glass vessels closed with Teflon-sealed lids with an inlet for purified pressurized air and an outlet for sampling. VOC samples were collected for $0.5 \mathrm{~h}$ on about $150 \mathrm{mg}$ TenaxTA adsorbent (Supelco, mesh 60/80) from plant headspace through Teflon tubing. The flow rate was set to $0.2151 \mathrm{~min}^{-1}$ for the compensation air and $0.2001 \mathrm{~min}^{-1}$ for the sampling. The VOC collection was performed at $22^{\circ} \mathrm{C}$ and at $250 \mu \mathrm{mol} \mathrm{m}^{-2} \mathrm{~s}^{-1}$ PAR at ambient $\mathrm{CO}_{2}$ and zero $\mathrm{O}_{3}$ concentration. Samples were analyzed by gas chromatographymass spectrometry (GC-MS, Hewlett Packard GC type 6890, MSD 5973) after desorption (Perkin Elmer ATD400). Emissions were calculated as ng $(\mathrm{g} \text { dry weight })^{-1} \mathrm{~h}^{-1}$. The sample analysis has been described in detail elsewhere (Vuorinen et al., 2004b).

\subsection{Aerosol formation experiments}

Figure 1 shows an experimental set-up used in aerosol formation experiments. The experiments were carried out in a $2.6 \mathrm{~m}^{3}$ growth chamber (Bioklim 2600T, height $1.75 \mathrm{~m}$, bottom area $1.55 \mathrm{~m} \times 0.97 \mathrm{~m}$, inner walls special painted aluminium, lights insulated from chamber air with a polyacrylic plate) (Holopainen and Kärenlampi, 1984). MeJA-treated cabbage plants (40 cv. Lennox and $35 \mathrm{cv}$. Rinda) were situated on a wire-net table about $0.20 \mathrm{~m}$ above the bottom of the chamber in similar growth conditions as described earlier. Aerosol samples were taken at the height of about $0.5 \mathrm{~m}$ above the plants. During the ozonolysis experiments, a forced air circulation in the chamber was turned off to prevent particle losses and condensation of volatile vapors to the heat exchanger of the air circulation system. Furthermore, the intensity of the lights was reduced from nominal values to the level of about $100 \mu \mathrm{mol} \mathrm{m}^{-2} \mathrm{~s}^{-1}$ PAR to prevent increase in temperature. Filtered pressurized air flow of about $51 \mathrm{~min}^{-1}$ was fed to the chamber to carry $\mathrm{O}_{3}$ as well as to keep it slightly over pressured during the experiments. $\mathrm{O}_{3}$ was generated from pure oxygen (Fisher $\mathrm{OZ}_{500 \mathrm{O}_{3} \text { genera- }}$ tor) and continuously monitored (Dasibi Model 1008-RS O 3 analyzer). In addition, relative humidity $(R H)$ and temperature were determined continuously with a $R H$ and temperature transmitter (Vaisala Humitter Y50) at the height of about $0.5 \mathrm{~m}$ above the plants.

Prior to the aerosol formation experiments, VOC's in the chamber air were collected before and after ozone pulses with a Perkin Elmer Sequential Tube Sampler (Model STS 25) into Tenax-TA tubes. The samples were collected directly from the air without any ozone absorbent and the collection sequence was two hours. The VOC samples were analyzed as described earlier.

Particle formation and growth during $\mathrm{O}_{3}$ exposure in the chamber was determined by measuring the aerosol particle number size distributions with a differential mobility particle 


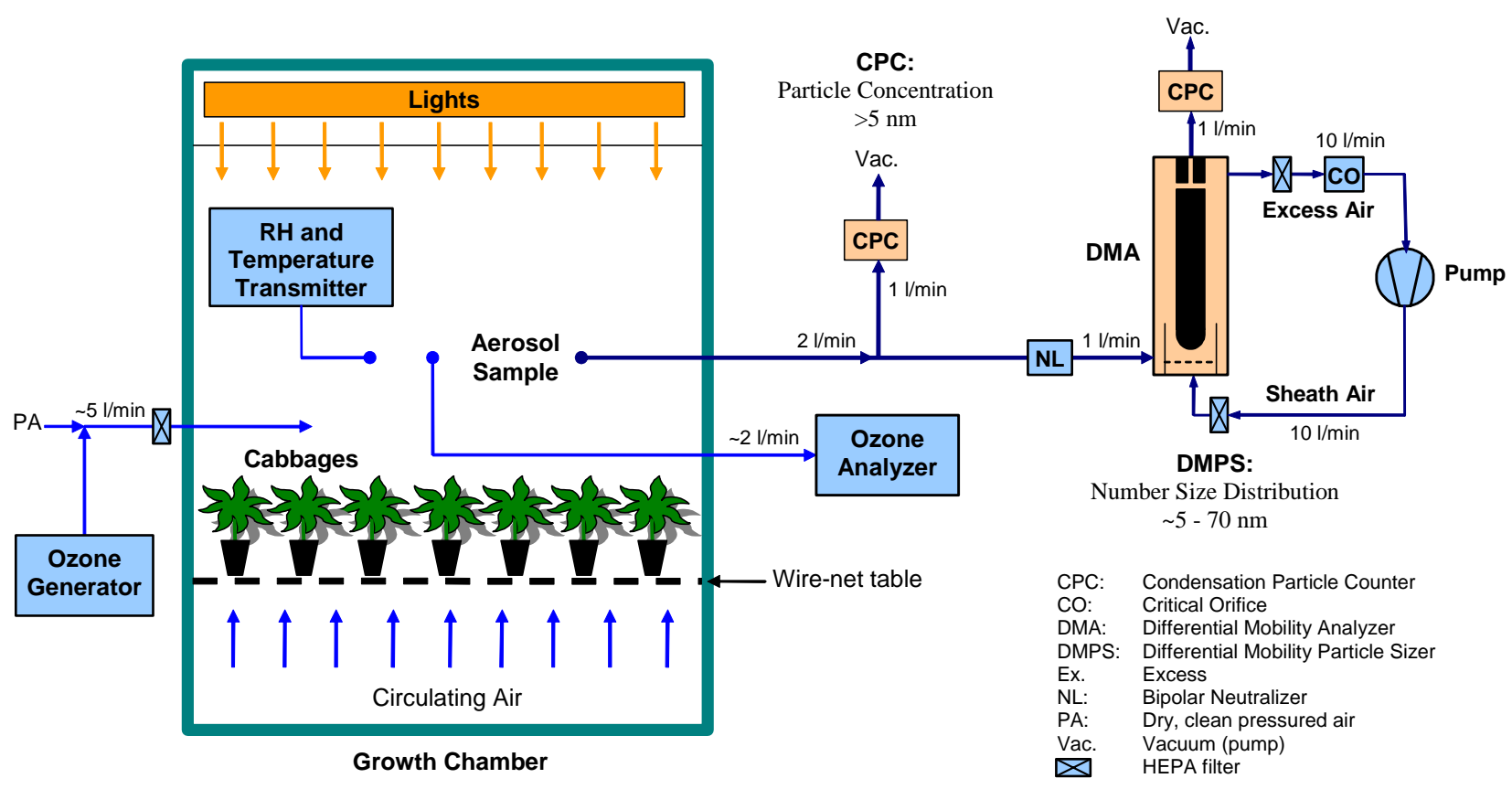

Fig. 1. Experimental setup used in aerosol formation experiments during ozone pulses over treated cabbage plants.

sizer (DMPS, Knutson and Whitby, 1975). The particle size distributions were measured every $7 \mathrm{~min}$ in the size range of $5.5-70 \mathrm{~nm}$. In addition, total number concentration of particles starting from about $5 \mathrm{~nm}$ up to several micrometers in diameter was measured with a condensation particle counter (CPC, TSI Model 3010) with a time resolution of $10 \mathrm{~s}$. The DMPS system consists of a $10.9 \mathrm{~cm}$ long Hauketype differential mobility analyzer (DMA, Winklmayr et al., 1991), which is used to classify the aerosol particles based on their electrical mobility, and a condensation particle counter (CPC, TSI Model 3010), which is used to measure the concentration of size-classified particles. The DMA was operated with aerosol and sheath flows of 1 and $101 \mathrm{~min}^{-1}$, respectively, and the sheath and excess flows were controlled by a closed-loop flow arrangement with a critical orifice. The sample aerosol was neutralized with a radioactive $\beta$-source (Ni-63) before the DMA. To measure particles down to about $5 \mathrm{~nm}$ in diameter, the temperature difference between saturator and condenser was increased to $25^{\circ} \mathrm{C}$ in both CPCs (Mertes et al., 1995). From the measured DMPS data, particle size distributions were determined using a Tichonov regularization method with a smoothness constraint (Voutilainen et al., 2001). CPC counting efficiency and diffusional particle losses in the tubing and the DMA were taken into account in the data analysis.

Before particle production experiments with plants, blank chamber tests were performed in order to determine effects of impurities in the empty chamber

\section{Results and discussion}

\subsection{Plant experiments}

Table 1 shows results form the GC-MS analyses of the emissions from the control (intact) and MeJA-treated cabbages for cultivars Lennox and Rinda. The results indicated 2 to 10fold increase in monoterpene emissions from MeJA treated plants. In addition, homoterpene (E)-4,8-dimethyl-1,3,7nonatriene (DMNT), sesquiterpene $(E, E)-\alpha$-farnesene, and (Z)-3-hexenyl acetate which are typical to cabbage plants damaged by diamondback moth larvae (Vuorinen et al., 2004b) were emitted from MeJA-treated plants. In cultivar Rinda, control plants also emitted green leaf volatiles (GLVs, (Z)-3-hexen-1-ol, (E)-2-hexenal and (Z)-3-hexenyl acetate) and sesquiterpene $(E, E)$ - $\alpha$-farnesene indicating possible mechanical damage during handling.

The results show that MeJA-treated plants are more efficient in releasing aerosol precursors than non-treated intact plants, suggesting that inducible VOCs released by stressed plants are important aerosol particle precursors also at the canopy level.

The analyses of samples from chamber air 14 to $24 \mathrm{~h}$ after MeJA spraying of the plants (both cultivars) but prior to $\mathrm{O}_{3}$ pulses, indicated that all the terpenoids listed in Table 1 were detectable except for DMNT. Limonene, $(E, E)$ $\alpha$-farnesene, sabinene and $\alpha$-thujene were the most abundant terpenes in the air before noon. Figure 2 shows the change of the VOC concentrations in chamber air during an ozone pulse over MeJA-treated plants. The sesquiterpene $\alpha$-farnesene 
Table 1. VOC (terpenes and two green leaf volatiles) emissions $\left( \pm \mathrm{SD}, \mathrm{ng} \mathrm{g}^{-1} \mathrm{~d} . \mathrm{w}^{\mathrm{h}} \mathrm{h}^{-1}\right)$ of cabbage cultivars Lennox and Rinda. VOCs were analyzed from intact (control) and MeJA-treated (sprayed with $10 \mathrm{mM}$ MeJA 4 days prior to the experiments) cabbage plants ( $n=5$ per cv.). Asterisks denote statistically significant $(P<0.05$, Mann-Whitney U-test) difference between treatment means among the cultivar. Superscripts MT, HT, ST, and GLV denote a class of VOC: monoterpene, homoterpene, sesquiterpene, and green leaf volatile, respectively. $\mathrm{DMNT}=(E)-4,8$-dimethyl-1,3,7-nonatriene.

\begin{tabular}{|c|c|c|c|c|}
\hline & \multicolumn{2}{|c|}{ cv. Lennox } & \multicolumn{2}{|c|}{ cv. Rinda } \\
\hline & Control & MeJA & Control & MeJA \\
\hline$\alpha$-thujene ${ }^{\mathrm{MT}}$ & $1.4 \pm 3.2$ & $36.7 \pm 9.6^{*}$ & $8.2 \pm 5.3$ & $37.6 \pm 12.7 *$ \\
\hline$\alpha$-pinene ${ }^{\mathrm{MT}}$ & 0 & $20.7 \pm 3.7 *$ & $1.0 \pm 2.2$ & $20.9 \pm 9.3^{*}$ \\
\hline sabinene $^{\mathrm{MT}}$ & $11.3 \pm 11.6$ & $115.1 \pm 25.4^{*}$ & $5.2 \pm 11.5$ & $115.9 \pm 53.4 *$ \\
\hline$\beta$-pinene $\mathrm{MT}^{\mathrm{MT}}+$ myrcene $^{\mathrm{MT}}$ & 0 & $47.2 \pm 10.8^{*}$ & $11.54 \pm 1.0$ & $47.6 \pm 21.6^{*}$ \\
\hline limonene $\mathrm{e}^{\mathrm{MT}}$ & $30.1 \pm 14.2$ & $377.8 \pm 96.4 *$ & $55.64 \pm 70.79$ & $133.2 \pm 85.2$ \\
\hline 1,8 -cineole ${ }^{\mathrm{MT}}$ & $18.5 \pm 6.0$ & $61.9 \pm 11.0 *$ & $39.27 \pm 47.56$ & $81.7 \pm 44.2$ \\
\hline $\mathrm{DMNT}^{\mathrm{HT}}$ & 0 & $76.5 \pm 23.7 *$ & 0 & $41.0 \pm 10.4 *$ \\
\hline$(\mathrm{E}, \mathrm{E})-\alpha$-farnesene $\mathrm{ST}^{\mathrm{ST}}$ & 0 & $26.1 \pm 19.8$ & $3.94 \pm 8.80$ & $43.2 \pm 22.7 *$ \\
\hline Total terpene emission & $61.3 \pm 8.1$ & 761.9 $\pm 143.8 *$ & $124.8 \pm 115.5$ & $521.1 \pm 235.4$ \\
\hline (Z)-3-hexen-1-ol+( $E$ )-2-hexenal GLV & 0 & $39.5 \pm 53.7$ & $87.81 \pm 138.90$ & 0 \\
\hline (Z)-3-hexenyl acetate $\mathrm{GLV}$ & 0 & $146.2 \pm 169.2 *$ & $160.2 \pm 189.6$ & $35.2 \pm 23.9$ \\
\hline Total VOC emission & $61.3 \pm 8.1$ & $947.5 \pm 362.5 *$ & $372.8 \pm \mathbf{3 1 9 . 3}$ & $556.3 \pm 224.4$ \\
\hline
\end{tabular}

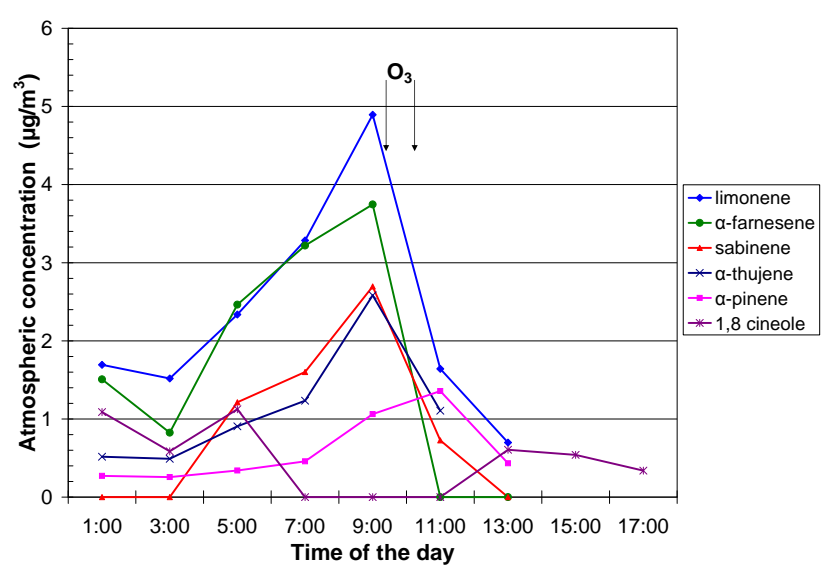

Fig. 2. Average concentrations of several VOCs in chamber air over MeJA-treated cabbage plants during an ozone pulse experiment (experiment carried out a day prior to aerosol formation experiments). The arrows indicate the start and end times of the ozone pulse. The collection time was $2 \mathrm{~h}$ per sample.

was detectable in the chamber air at similar concentration levels as the monoterpenes, but unlike the monoterpenes it disappeared from the samples just after the first ozone peak. We expect that this disappearance indicated rather $\alpha$ farnesene depletion due to atmospheric reactions than rapid adsorption to the walls.

For comparison, the main VOCs emitted from Scots pine (one of the most common species in the boreal forest) are $\Delta^{3}$ carene, $\alpha$-pinene and $\beta$-pinene according to recent measurements in two locations in Finland (Tarvainen et al., 2004).
They contribute $60-85 \%$ of the total observed monoterpene emission rates. Globally the main monoterpenes are $\alpha$ pinene, $\beta$-pinene and limonene (Kanakidou et al., 2004; Guenther et al., 1995). The spectrum of the VOCs emitted by the cabbages is somewhat different from the emission spectrum of e.g. Scots pine forests. However, we believe that cabbage as natural monoterpene-emitter is more representative of atmospheric reaction conditions than the pure VOCs or mixtures of pure VOCs commonly used in smog chamber experiments.

\subsection{Blank chamber tests}

Two sets of blank chamber tests were performed to determine effects of impurities in the empty chamber. In the first set, we observed particle production during the first ozonolysis of an empty chamber, but no aerosols were formed during subsequent periods when $\mathrm{O}_{3}$ was introduced into the chamber. We interpret this as a wall effect: volatile organics produced by plants that were placed in the chambers previously had adsorbed on chamber walls and reacted with $\mathrm{O}_{3}$ during the first ozonolysis experiment forming new particles. During the ozonolysis, those organics were depleted from the walls and therefore no particle production was observed afterwards. The second blank chamber test set was performed after the experiments with MeJA-treated plants. In this set, no nucleation was observed during chamber ozonolysis. This confirmed that the aerosol nucleation events observed during the plant ozonolysis experiments were actually caused by species emitted by the plants and not by impurities on the chamber walls. 


\subsection{Aerosol formation experiments}

Figure 3 shows a contour plot of aerosol particle number size distributions, total aerosol particle number and $\mathrm{O}_{3}$ concentrations, temperature and $R H$ during aerosol formation experiments over MeJA-treated plants. Rapid particle production was observed during two consecutive ozonolysis (400 and 270 ppbv $\mathrm{O}_{3}$, respectively) experiments. Background particle number concentration and average particle diameter were about $2700 \mathrm{~cm}^{-3}$ and $35 \mathrm{~nm}$, respectively, before the first ozone pulse. During the ozonolysis, particle concentration increased to about $5500 \mathrm{~cm}^{-3}$ within $15 \mathrm{~min}$ and then started to decrease due to particle coagulation and deposition. During the second experiment about 3 hours later, particle concentration increased from 950 to $3000 \mathrm{~cm}^{-3}$ in 15 min. Relative humidity varied between $31-44 \%$ and temperature between $26-30^{\circ} \mathrm{C}$ during the experiments.

The most important quantities characterizing the intensity of the new particle formation events are particle formation rate (number of particles formed in unit volume and time) and growth rate (increase of particle diameter in unit time). The former is dependent on condensable vapor supersaturation level, while the latter depends on the absolute difference between the partial pressure and the saturation vapor pressure. The particle formation rates (or more precisely, $5 \mathrm{~nm}$ particle appearance rates) during the nucleation events were 3.1 and $2.3 \mathrm{~cm}^{-3} \mathrm{~s}^{-1}$. These numbers are well comparable to particle formation rates observed in ambient air, which vary between $0.01-10 \mathrm{~cm}^{-3} \mathrm{~s}^{-1}$ in the continental boundary layer (Kulmala et al., 2004). The particle growth rates, on the other hand, were on the order of $40-70 \mathrm{~nm} \mathrm{~h}^{-1}$, corresponding to condensable vapor mixing ratios of $0.02-0.03 \mathrm{ppbv}$. The growth rates of particles formed in atmospheric nucleation events, as well as the corresponding condensable vapor mixing ratios, are usually an order of magnitude lower, the maximum observed growth rate being $20 \mathrm{~nm} \mathrm{~h}^{-1}$ (Kulmala et al., 2004).

The disparity between particle growth rates in our experiments and in the atmosphere contradicts the theory (Bonn and Moortgat, 2003) that atmospheric nucleation events are caused by homogeneous nucleation of ozonolysis products of volatile compounds released by plants: our experiments show that the condensable vapor concentrations required to produce the nucleation are roughly ten times higher than those related to atmospheric particle formation events. (Note, however, that the experiments of Bonn and Moortgat (2003) were carried out at lower temperatures than ours, corresponding more to nucleation temperatures in springtime Finland (Kulmala et al., 2004), whereas our experimental temperatures were similar as temperatures during nucleation events recorded in the Po Valley in July (Laaksonen et al., 2005).) Furthermore we did not shield the growth chamber from cosmic rays, radon, or radioactivity from the building walls, so that ions have been created in the chamber air during our experiments. Simple Geiger counter measurements outside the
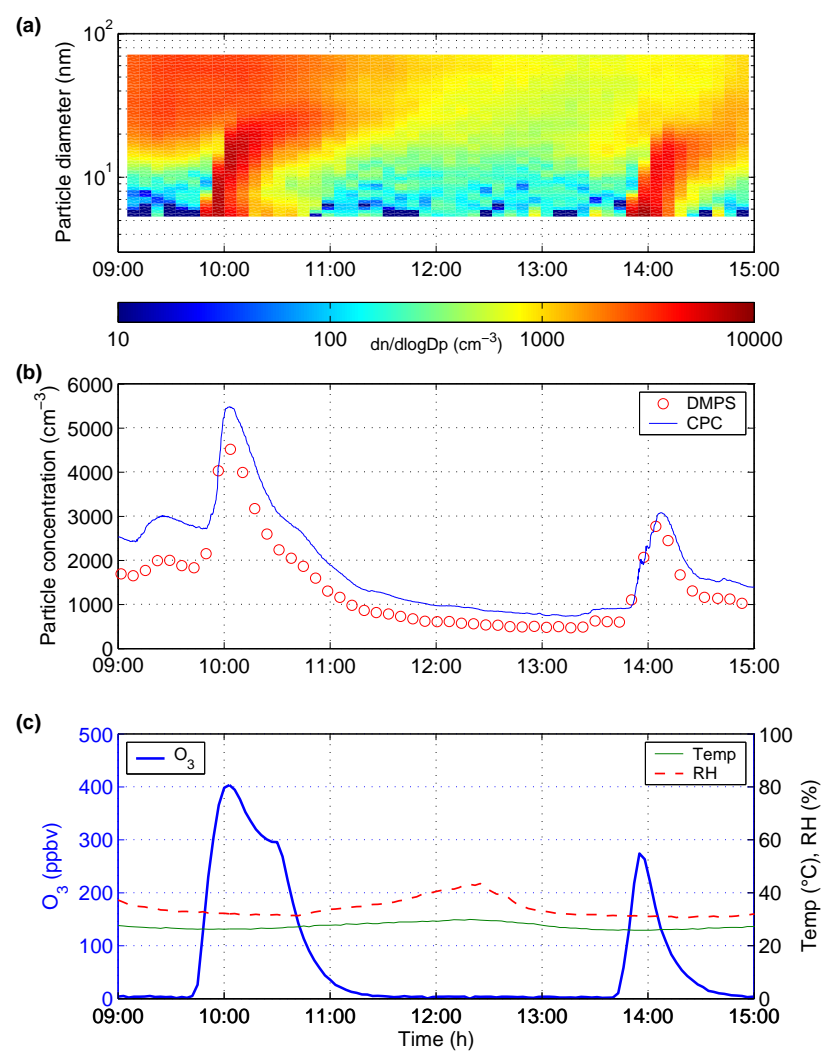

Fig. 3. Fine particle nucleation over MeJA-treated cabbage plants (cvs. Lennox and Rinda): (a) a contour plot of aerosol particle number size distributions (measured with the DMPS), (b) aerosol particle number concentrations (from DMPS and CPC results), and (c) ozone $\left(\mathrm{O}_{3}\right)$ concentration, relative humidity $(R H)$ and temperature (Temp) during two consecutive ozonolysis experiments.

laboratory building and inside the growth chamber showed that dose rates were about 0.1 and 0.08 microsieverts per hour, respectively. The ionization rate during the nucleation experiments may therefore have been on the same order as the observed particle formation rates, and it is therefore possible that the nucleation we observed was ion-induced. But whatever the actual nucleation mechanism, the required vapor concentrations are still higher than what are needed for atmospheric nucleation. Our results therefore also contradict the possibility that atmospheric particle formation events are caused by ion-induced nucleation of oxidized organics.

Although it seems that the nucleation in our growth chamber proceeded with a different mechanism than in the atmosphere, we believe that our experimental results are relevant to atmospheric conditions. Another theory put forward recently (see e.g. Kulmala, 2003) holds that in the atmosphere, thermodynamically stable molecular clusters with diameters of about $1 \mathrm{~nm}$ are formed due to clustering of sulfuric acid and possibly ammonia and water molecules. Subsequently, other, presumably organic, vapors are needed to nucleate heterogeneously on the sulfate clusters, speeding up 
cluster growth so that the clusters survive to detectable sizes $(>3 \mathrm{~nm}$ ) before they are scavenged due to coagulation with larger particles. In our experiments, there were no sulfate clusters present, and hence the non-volatile organics formed in the ozonolysis reactions nucleated homogeneously (even if some $\mathrm{SO}_{2}$ had managed to get through the pressurized air filtration system, there would not have been enough of $\mathrm{OH}$ radicals present for significant sulfuric acid formation). The supersaturation required for homogeneous nucleation is higher than that required for heterogeneous nucleation and thus the organic vapor levels needed for particle production are higher in the chamber experiments compared with the atmosphere. This would explain why we observe more rapid growth of particles than what is encountered in atmospheric conditions, and our results are thus consistent with Kulmala's theory although they do not prove that the theory is correct.

Furthermore, the absence of nucleation events in the Amazon suggests that new particle formation purely from SOA compounds may not be frequent in environments with very high biogenic VOC concentrations but very low sulfur concentrations (Kanakidou et al., 2004). The conditions in our experiments are similar with the exception of higher $\mathrm{O}_{3}$ concentration that can induce particle formation via homogenous nucleation. This also supports our suggestion that the main particle formation mechanism in the atmosphere is condensation (or absorption followed by chemical reactions) of oxidized organics on pre-existing molecular clusters rather than homogeneous or ion-induced nucleation of oxidized organics.

\section{Conclusions}

We have studied formation and growth of aerosol particles over white cabbage plants during $\mathrm{O}_{3}$ exposure in a growth chamber. The plants had been treated with methyl jasmonate (MeJA) elicitor to artificially initiate an emission spectrum that is typical to herbivore-damaged plants and to induce emissions of homo- and sesquiterpenes. In addition, we have determined emissions of volatile organic compounds (VOCs) from individual intact (control) and MeJA-treated plants for emission comparison.

The VOC emission analyses from individual plants show that MeJA-treated plants are more efficient in releasing aerosol precursors than non-treated plants (nearly 26-fold increase in emissions of some monoterpenes), suggesting that inducible VOCs released by stressed plants are important aerosol particle precursors at the canopy level. Current estimates of phytogenic VOC emissions have predominantly assessed isoprene and monoterpene emission rates of different plant species (Kesselmeier and Staudt, 1999). To better assess aerosol forming capacity of vegetation, it is essential to evaluate the whole emitted VOC spectrum of different plant species including sesquiterpenes and other inducible terpenes. Furthermore, herbivore-induced compounds re- leased by damaged plants attract the natural enemies of herbivores, and thereby defend plants indirectly. However, during peak $\mathrm{O}_{3}$ episodes inducible VOCs released after herbivore damage may degrade fast and lose their ecological signaling value (Holopainen, 2004) to natural enemies of herbivores. Recently, it has been proposed that crop plants should be genetically engineered to produce these inducible volatiles (Degenhardt et al., 2003). Cultivation of such "self defending" crops might reduce pesticide use, but air pollutants (e.g. $\mathrm{O}_{3}, \mathrm{NO}_{\mathrm{x}}$ ) that destroy emitted volatiles could decrease the efficiency of this strategy.

Our aerosol particle size distribution measurements showed rapid particle formation during ozonolysis experiments. To our knowledge, aerosol production due to ozonolysis of plant-released VOCs has not been demonstrated in the laboratory prior to this work. The observed particle formation rates were well in the range observed in atmospheric nucleation events; however, particle growth rates were clearly higher. The results indicate that the concentrations of nonvolatile oxidation products of plant released precursors needed to induce the nucleation are roughly an orderof-magnitude higher than their concentrations during atmospheric nucleation events. Our results are therefore consistent with the suggestion that atmospheric nucleation events proceed via condensation (or absorption followed by chemical reactions) of oxidized organics on pre-existing molecular clusters rather than via their homogeneous or ion-induced nucleation.

Acknowledgements. This work was supported by the Academy of Finland, decisions no. 105209 and 202300 (M. Loivamäki, T. Vuorinen, A.-M. Nerg, J. K. Holopainen) project 52476 and the Center of Excellence program (A. Laaksonen, J. Joutsensaari) and by Emil Aaltonen Foundation (J. Joutsensaari and P. Miettinen). The authors want to thank T. Oksanen for his help during the experiments and the staff at the Kuopio University Research Garden for maintaining the plants.

Edited by: M. Kulmala

\section{References}

Anderson, T. L., Charlson, R. J., Schwartz, S. E., Knutti, R., Boucher, O., Rodhe, H., and Heintzenberg, J.: Climate forcing by aerosols - a hazy picture, Science, 300, 1103-1104, 2003.

Bonn, B. and Moortgat, G. K.: Sesquiterpene ozonolysis: Origin of atmospheric new particle formation from biogenic hydrocarbons, Geophys. Res. Lett., 30, 1585, doi:10.1029/2003GL017000, 2003.

Claeys, M., Graham, B., Vas, G., Wang, W., Vermeylen, R., Pashynska, V., Cafmeyer, J., Guyon, P., Andreae, M. O., Artaxo, P., and Maenhaut, W.: Formation of secondary organic aerosols through photooxidation of isoprene, Science, 303, 1173-1176, 2004.

Degenhardt, J., Gershenzon, J., Baldwin, I. T., and Kessler, A.: Attracting friends to feast on foes: engineering terpene emission to make crop plants more attractive to herbivore enemies, Curr. Opin. Biotechnol., 14, 169-176, 2003. 
Dicke, M. and van Loon, J. J. A.: Multitrophic effects of herbivoreinduced plant volatiles in an evolutionary context, Entomol. Exp. Appl., 97, 237-249, 2000.

Guenther, A., Hewitt, C.N., Erickson, D., Fall, R., Geron, C., Graedel, T., Harley, P., Klinger, L., Lerdau, M., Mckay, W.A., Pierce, T., Scholes, B., Steinbrecher, R., Tallamraju, R., Taylor, J., Zimmerman, P.: A global model of natural volatile organic compound emissions, J. Geophys. Res., 100(D5), 8873-8892, 1995.

Holopainen, T. and Kärenlampi, L.: Injuries to lichen ultrastructure caused by sulphur dioxide fumigations, New Phytol., 98, 285294, 1984

Holopainen, J. K.: Multiple functions of inducible plant volatiles, Trends Plant Sci., 9, 529-533, 2004.

Kanakidou, M., Seinfeld, J. H., Pandis, S. N., Barnes, I., Dentener, F. J., Facchini, M. C., Van Dingenen, R., Ervens, B., Nenes, A., Nielsen, C. J., Swietlicki, E., Putaud, J. P., Balkanski, Y., Fuzzi, S., Horth, J., Moortgat, G. K., Winterhalter, R., Myhre, C. E. L., Tsigaridis, K., Vignati, E., Stephanou, E. G., and Wilson, J.: Organic aerosol and global climate modelling: A review, Atmos. Chem. Phys., 5, 1053-1123, 2005,

SRef-ID: 1680-7324/acp/2005-5-1053

Kavouras, I. G., Mihalopoulos, N., and Stephanou, E. G.: Formation of atmospheric particles from organic acids produced by forests, Nature, 395, 683-686, 1998.

Kesselmeier, J. and Staudt, M.: Biogenic volatile organic compounds (VOC): An overview on emission, physiology and ecology, J. Atmos. Chem., 33, 23-88, 1999.

Knutson, E. O. and Whitby, K. T.: Aerosol classification by electric mobility: apparatus, theory and applications, J. Aerosol Sci., 6, 443-451, 1975.

Kulmala, M.: How particles nucleate and grow, Science, 302, 10001001, 2003.

Kulmala, M., Vehkamäki, H., Petäjä, T., Dal Maso, M., Lauri, A., Kerminen, V.-M., Birmili, W., and McMurry, P. H.: Formation and growth rates of ultrafine atmospheric particles: a review of observations, J. Aerosol Sci., 35, 143-176, 2004.
Laaksonen, A., Hamed, A., Joutsensaari, J., Hiltunen, L. Cavalli, F., Junkermann, W., Asmi, A., Fuzzi, F., and Facchini, M. C.: Cloud condensation nucleus production from nucleation events at a highly polluted region, Geophys. Res. Lett., 32, L06812, doi:10.1029/2004GL022092, 2005.

Loivamäki, M., Holopainen, J. K., and Nerg, A.-M.: Chemical changes induced by methyl jasmonate in oilseed rape grown in the laboratory and in the field, J. Agric. Food Chem., 52 (25), 7607-7613, 2004.

Mattiacci, L., Dicke, M., and Posthumus, M. A.: Beta-Glucosidase - An Elicitor of Herbivore-Induced Plant Odor That Attracts Host-Searching Parasitic Wasps, Proc. Natl. Acad. Sci. U. S. A., 92, 2036-2040, 1995.

Mertes, S., Schroder, F., and Wiedensohler, A.: The particledetection efficiency curve of the TSI-3010 CPC as a function of the temperature difference between saturator and condenser, Aerosol Sci. Technol., 23, 257-261, 1995.

Tarvainen, V., Hakola, H., Hellén, H., Bäck, J., Hari, P., and Kulmala, M.: Temperature and light dependence of the VOC emissions of Scots pine, Atmos. Chem. Phys., 5, 989-998, 2005, SRef-ID: 1680-7324/acp/2005-5-989.

Voutilainen, A., Kolehmainen, V., and Kaipio, J. P.: Statistical inversion of aerosol size measurement data, Inverse Probl. Eng., 9 , 67-94, 2001.

Vuorinen, T., Nerg, A. M., and Holopainen, J. K.: Ozone exposure triggers the emission of herbivore-induced plant volatiles, but does not disturb tritrophic signalling, Environ. Pollut., 131, 305-311, 2004a.

Vuorinen, T., Nerg, A. M., Ibrahim, M. A., Reddy, G. V. P., and Holopainen, J. K.: Emission of Plutella xylostella-induced compounds from cabbages grown at elevated $\mathrm{CO}_{2}$ and orientation behavior of the natural enemies, Plant Physiol., 135, 1984-1992, 2004b.

Winklmayr, W., Reischl, G. P., Lindner, A. O., and Berner, A.: A new electromobility spectrometer for the measurement of aerosol size distributions in the size range from 1 to $1000 \mathrm{~nm}$, J. Aerosol Sci., 22, 289-296, 1991. 